\title{
Co-self-assembly of cationic microparticles to deliver pEGFP-ZNF580 for promoting the transfection and migration of endothelial cells
}

This article was published in the following Dove Press journal:

International Journal of Nanomedicine

20 December 2016

Number of times this article has been viewed

\author{
Yakai Feng, ${ }^{1-5}$ Mengyang \\ Guo,' Wen Liu,' Xuefang \\ Hao,' Wei Lu,' Xiangkui \\ Ren, ${ }^{1,2}$ Changcan Shi, ${ }^{4,5}$ \\ Wencheng Zhang6 \\ 'Department of Polymer Science \\ and Engineering, School of Chemical \\ Engineering and Technology, \\ Collaborative Innovation Center \\ of Chemical Science and Chemical \\ Engineering (Tianjin), Tianjin \\ University, ${ }^{2}$ Tianjin University- \\ Helmholtz-Zentrum Geesthacht, \\ Joint Laboratory for Biomaterials \\ and Regenerative Medicine, ${ }^{3}$ Key \\ Laboratory of Systems Bioengineering \\ of Ministry of Education, Tianjin \\ University, Tianjin, ${ }^{4}$ Institute of \\ Biomaterials and Engineering, \\ Wenzhou Medical University, \\ ${ }^{5}$ Wenzhou Institute of Biomaterials \\ and Engineering, CNITECH, \\ CAS, Wenzhou, ${ }^{6}$ Department of \\ Physiology and Pathophysiology, \\ Logistics University of Chinese \\ People's Armed Police Force, Tianjin, \\ People's Republic of China
}

Correspondence: Xiangkui Ren School of Chemical Engineering and Technology, Collaborative Innovation Center of Chemical Science and Chemical Engineering (Tianjin), Tianjin University, 92 Weijin Road, Tianjin 300072, People's Republic of China Tel/fax +86222740 I999

Email renxiangkui@tju.edu.cn

Changcan Shi

Wenzhou Institute of Biomaterials and Engineering, Wenzhou Medical University, I6 Xinsan Road, Wenzhou 3250I I, Zhejiang, People's Republic of China Tel/fax +86 57788017500

Email shicc@wibe.ac.cn

\begin{abstract}
The gene transfection efficiency of polyethylenimine (PEI) varies with its molecular weight. Usually, high molecular weight of PEI means high gene transfection, as well as high cytotoxicity in gene delivery in vivo. In order to enhance the transfection efficiency and reduce the cytotoxicity of PEI-based gene carriers, a novel cationic gene carrier was developed by co-self-assembly of cationic copolymers. First, a star-shaped copolymer poly(3(S)-methylmorpholine-2,5-dione-co-lactide) (P(MMD-co-LA)) was synthesized using D-sorbitol as an initiator, and the cationic copolymer (P(MMD-co-LA)-g-PEI) was obtained after grafting low-molecular weight PEI. Then, by co-self-assembly of this cationic copolymer and a diblock copolymer methoxy-poly(ethylene glycol) (mPEG)-b-P(MMD-co-LA), microparticles (MPs) were formed. The core of MPs consisted of a biodegradable block of P(MMD-co-LA), and the shell was formed by mPEG and PEI blocks. Finally, after condensation of pEGFP-ZNF580 by these MPs, the plasmids were protected from enzymatic hydrolysis effectively. The result indicated that pEGFP-ZNF580-loaded MP complexes were suitable for cellular uptake and gene transfection. When the mass ratio of mPEG-b-P(MMD-co-LA) to P(MMD-co-LA)-g-PEI reached $3 / 1$, the cytotoxicity of the complexes was very low at low concentration $\left(20 \mu \mathrm{g} \mathrm{mL}^{-1}\right)$. Additionally, pEGFP-ZNF580 could be transported into endothelial cells (ECs) effectively via the complexes of MPs/pEGFP-ZNF580. Wound-healing assay showed that the transfected ECs recovered in $24 \mathrm{~h}$. Cationic MPs designed in the present study could be used as an applicable gene carrier for the endothelialization of artificial blood vessels.
\end{abstract}

Keywords: star-shaped copolymer, microparticles, gene carrier, endothelial cells, transfection, migration

\section{Introduction}

Atherosclerotic vascular diseases have become the major cause of morbidity and mortality in recent years all over the world. ${ }^{1}$ Coronary bypass surgery is one of the most vital procedures for treating occluded coronary arteries. ${ }^{2,3}$ However, restenosis of artificial blood vessels usually leads to the failure of the surgery. To decrease or prevent the formation of thrombus, hydrophilic modification of the artificial blood vessels has been used and demonstrated to be an efficient strategy. Various strategies including hydrophilic surface modification have been explored by us and other researchers., ${ }^{4,5}$ For example, silk fiber, collagen, heparin, poly(ethylene glycol), gelatin, zwitterionic polynorbornene and 2-methacryloyloxyethyl phosphorylcholine have been widely used in surface modification of artificial blood scaffolds. ${ }^{6-14}$ The hydrophilicity, hemocompatibility and biocompatibility of artificial blood vessels have been improved greatly after surface modification. 
For preventing thrombosis, another effective strategy is to form endothelium on the luminal surface of artificial vascular grafts. Up to date, many strategies have been reported to promote the proliferation and migration of endothelial cells (ECs). ${ }^{15}$ For example, Mattix et al designed and manufactured magnetic vascular nanoparticles for rapid endothelialization to reduce the risk of restenosis. ${ }^{16}$ Moreover, after modification with anti-CD34 antibody on the surface of a stent, the attachment of ECs was promoted greatly. ${ }^{17}$

As a future therapeutic strategy, gene therapy has been bloomed over years. It has great potential in treating cancers, atherosclerotic vascular diseases and genetic disorders. ${ }^{18,19}$ Gene therapy is also an attractive method to realize rapid endothelialization, which has attracted wide interests of researchers..$^{20}$ For example, to enhance the proliferation of ECs, both vascular endothelial growth factor and plateletderived growth factor have been encapsulated in electrospun membranes with dual-delivery function. ${ }^{21}$ Furthermore, in the process of intervention for atherosclerosis and proliferation of ECs, ZNF580 gene plays an important role in promoting the proliferation of ECs and inhibiting the proliferation of smooth muscles. ${ }^{22}$ In our previous studies, several gene carriers to condense with pEGFP-ZNF580 gene (pEGFPZNF580 gene is the recombinant plasmid of enhanced GFP plasmid and ZNF580 gene) were prepared with different block copolymers for the proliferation of ECs. ${ }^{23-29}$

As the "gold" standard nonviral gene carrier, polyethylenimine (PEI) is widely used as an effective gene carrier, which exhibits a good performance in condensing DNA due to its high positive charge density. ${ }^{30}$ However, the drawbacks of high-molecular weight PEI, including nondegradability and high cytotoxicity, limit its application in vivo. ${ }^{31-33}$

In recent decades, the excellent properties of star-shaped polymers have attracted researchers' attention. Compared with linear counterparts, star-shaped polymers with the same molecular weight have showed higher transfection efficiency ${ }^{34-36}$ Moreover, compared with linear polymers, the amphiphilic star-shaped polymers show relatively small hydrodynamic radius, and low solution and melt viscosities. ${ }^{35}$ Plenty of star-shaped polycations containing a biocompatible core display excellent performance in gene therapy. For example, Yang et al synthesized a bioreducible star-shaped gene carrier consisting of a biocompatible polyhedral oligomeric silsesquioxane core and eight disulfide-linked poly(2-dimethylamino)ethyl methacrylate arms ${ }^{36}$ The eight corner organic groups could be easily used to immobilize functional groups, which could lower cytotoxicity and increase transfection efficiency. By group transfer polymerization, Georgiou et al synthesized a series of 2-(dimethylamino) ethyl methacrylate-b-methoxy hexa(ethylene glycol) methacrylate star-shaped copolymers which showed low toxicity and high transfection efficiency compared to that of homopolymer. ${ }^{37}$ Considering the excellent properties of star-shaped polymers and the good performance of ZNF580 gene for rapid endothelialization, it is interesting to investigate and develop a potential star-shaped polymeric gene carrier aiming at accelerating the proliferation of human ECs.

In the present investigation, low-molecular weight PEI was grafted onto the end of star-shaped hydrophobic polymers to reduce the cytotoxicity of high-molecular weight PEI. As a result, a cationic copolymer poly(3(S)-methylmorpholine-2,5-dione-co-lactide) (P(MMD-co-LA)-grafted PEI (P(MMD-co-LA)-g-PEI) was synthesized. Then, by co-self-assembly of P(MMD-co-LA)-g-PEI and methoxypoly(ethylene glycol) (mPEG) (mPEG-b-P(MMD-co-LA)), a series of microparticles (MPs) were prepared (Scheme 1). Moreover, pEGFP-ZNF580 was condensed with PEI located at the surface of the MPs. The properties of MPs and pEGFPZNF580-loaded MPs were evaluated. The cytotoxicity could be varied easily by changing the ratios of mPEG-b-P(MMDco-LA) to P(MMD-co-LA)-g-PEI in mixed shell. The proliferation rate of ECs was characterized by transfection efficiency and wound-healing assay.

\section{Materials and methods Materials}

mPEG (weight-average molecular weight $\left[\mathrm{M}_{\mathrm{w}}\right]=5,000 \mathrm{Da}$ and polydispersity index $=1.05$ ), PEI (branched PEI, $\mathrm{M}_{\mathrm{w}}=10 \mathrm{kDa}$ ), 1-ethyl-3-(3-dimethylaminopropyl)-carb odiimide hydrochloride (EDC), N-hydroxy succinimide (NHS), 4-dimethylamino pyridine (DMAP), D-sorbitol and stannous octoate $\left(\mathrm{Sn}(\mathrm{Oct})_{2}\right)$ were purchased from SigmaAldrich (St Louis, MO, USA). Lactide (LA) was purchased from Foryou Medical Device Co., Ltd. (Huizhou, People's Republic of China). 1,4-Dioxane, succinic anhydride triethylamine $\left(\mathrm{Et}_{3} \mathrm{~N}\right)$, toluene and dimethyl sulfoxide (DMSO) were obtained from Institute of Jiangtian Chemical (Tianjin, People's Republic of China) and were dried by reflux over $\mathrm{CaH}_{2}$ and distilled. pEGFP-ZNF580 was preserved by the Department of Physiology and Pathophysiology, Logistics University of Chinese People's Armed Police Force. 3(S)Methyl-morpholine-2,5-dione (MMD) was prepared using our previously reported method. ${ }^{3}$ 


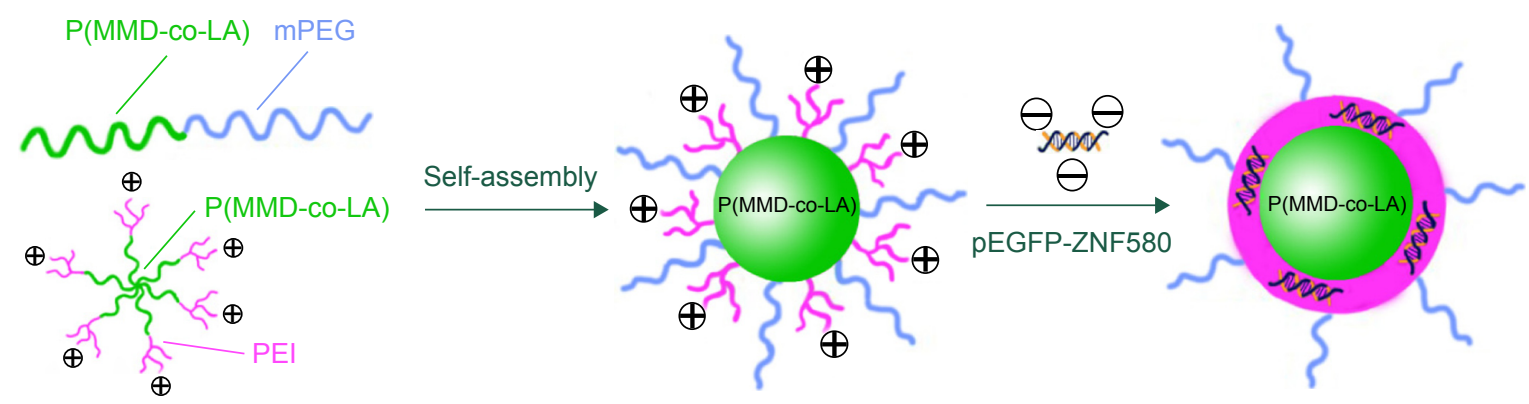

Scheme I Process of co-self-assembly of MPs and the formation of MPs/pEGFP-ZNF580 complexes.

Notes: The co-self-assembly of cationic copolymers P(MMD-co-LA)-g-PEl and mPEG-b-P(MMD-co-LA) could form a complex MPs system with a biodegradable P(MMDco-LA) core and a mixed mPEG/PEI shell. Then, ZNF580 gene was condensed with PEI located at the interface between P(MMD-co-LA) core and mPEG shell.

Abbreviations: MPs, microparticles; P(MMD-co-LA), poly(3(S)-methyl-morpholine-2,5-dione-co-lactide); PEl, polyethylenimine; mPEG, methoxy-poly(ethylene glycol).

\section{Synthesis of diblock copolymer}

Diblock copolymer mPEG-b-P(MMD-co-LA) was synthesized by ring-opening polymerization (ROP) as reported previously. ${ }^{27,31}$ First, $5.0 \mathrm{~g}$ of $\mathrm{mPEG}$ was placed into a Schlenk under nitrogen atmosphere. Second, $0.50 \mathrm{~g}$ of MMD, $4.5 \mathrm{~g}$ of $\mathrm{LA}$ and $400 \mu \mathrm{L}$ of $0.25 \mathrm{~mol} \mathrm{~L}^{-1} \mathrm{Sn}(\mathrm{Oct})_{2}$ solution were added successively into the Schlenk, which was full of nitrogen. Finally, the Schlenk was immersed into an oil bath $\left(120^{\circ} \mathrm{C}\right.$, $24 \mathrm{~h}$ ). The copolymer was purified and dried at room temperature in vacuum for $24 \mathrm{~h}$ afterward.

\section{Synthesis of $\mathrm{P}(M M D-c o-L A)-g-P E I$ cationic copolymer}

Synthesis of star-shaped copolymer

Using D-sorbitol as the initiator, $\mathrm{P}(\mathrm{MMD}$-co-LA) was prepared by ROP of MMD and LA as reported previously..$^{27,31}$ Briefly, $0.03 \mathrm{~g}$ of D-sorbitol, $4.50 \mathrm{~g}$ of LA and $0.50 \mathrm{~g}$ of MMD were added into the Schlenk full of nitrogen. Then, the Schlenk was immersed in an oil bath at $125^{\circ} \mathrm{C}$ for $24 \mathrm{~h}$. The copolymer was purified and dried at room temperature in vacuum for $24 \mathrm{~h}$. The yield was $79.4 \%$.

\section{Synthesis of star-shaped P(MMD-co-LA)-COOH}

Star-shaped $\mathrm{P}(\mathrm{MMD}-\mathrm{co}-\mathrm{LA})-\mathrm{COOH}$ copolymer was synthesized as reported previously. ${ }^{31} \mathrm{P}$ (MMD-co-LA) (3.0 g) was dissolved in dry 1,4-dioxane in a Schlenk flask $(25 \mathrm{~mL})$. Then, succinic anhydride $(1.2 \mathrm{~g}), \mathrm{Et}_{3} \mathrm{~N}(400 \mu \mathrm{L})$ and DMAP $(1.5 \mathrm{~g})$ were added in a three-necked flask. The reaction was performed at $25^{\circ} \mathrm{C}$ for $24 \mathrm{~h}$ under a dry nitrogen atmosphere. The copolymer was purified, and the chloroform solution was washed with hydrochloric acid aqueous solution $(10 \%, \mathrm{v} / \mathrm{v})$, saturated sodium bicarbonate solution and saturated sodium chloride solution three times, respectively. Finally, after rotary evaporation, star-shaped $\mathrm{P}(\mathrm{MMD}-\mathrm{co}-\mathrm{LA}) \mathrm{COOH}$ copolymer was obtained. The copolymer was dried at room temperature in vacuum.

Synthesis of cationic copolymer P(MMD-co-LA)-g-PEI Cationic copolymer P(MMD-co-LA)-g-PEI was synthesized as reported previously. ${ }^{31} \mathrm{P}(\mathrm{MMD}-\mathrm{co}-\mathrm{LA})-\mathrm{COOH}(0.30 \mathrm{~g})$, EDC $(0.06 \mathrm{~g})$ and NHS $(0.03 \mathrm{~g})$ were dissolved into $10 \mathrm{~mL}$ of DMSO and reacted at $25^{\circ} \mathrm{C}$ for $2 \mathrm{~h}$. The solution was dripped into $5.0 \mathrm{~mL}$ of PEI solution (1.5 g, $10 \mathrm{kDa}$ in DMSO). The mixture was stirred $\left(25^{\circ} \mathrm{C}, 24 \mathrm{~h}\right)$ and dialyzed. Finally, the solution was lyophilized to obtain the cationic copolymer P(MMD-co-LA)-g-PEI.

\section{Characterization of copolymers}

Copolymer structures were characterized by Fourier transform infrared (FT-IR) spectrometer (FTS-6000; Bio-Rad Laboratories Inc., Hercules, CA, USA) and proton nuclear magnetic resonance ( ${ }^{1} \mathrm{H}$ NMR) spectrum (AV-400; Bruker Corporation, Billerica, MA, USA). The number-average molecular weight $\left(M_{\mathrm{n}}\right)$ of copolymers was obtained by gel permeation chromatography (GPC; Viscotek; Malvern Instruments, Malvern, UK; tetrahydrofuran was used as the eluent).

\section{Preparation of MPs with different ratios of cationic copolymer and diblock copolymer mPEG-b-P(MMD-co-LA)}

MPs with different ratios of cationic copolymer and diblock copolymer mPEG-b-P(MMD-co-LA) were prepared as reported previously. ${ }^{24}$ Briefly, $\mathrm{P}(\mathrm{MMD}-\mathrm{co}-\mathrm{LA})$-g-PEI and mPEG-b-P(MMD-co-LA) were separately dissolved in DMSO $\left(5.0 \mathrm{mg} \mathrm{mL} \mathrm{m}^{-1}\right.$ ). Different volumes of copolymer solutions were blended to form suspension with various mass ratios. To $5.0 \mathrm{~mL}$ of phosphate-buffered saline (PBS), $1.0 \mathrm{~mL}$ of the blended polymer solution was added dropwise to form MPs. 


\section{Preparation of MPs/pEGFP-ZNF580 complexes}

The concentration of pEGFP-ZNF580 was $0.10 \mathrm{mg} \mathrm{mL}^{-1}$. To prepare MPs/pEGFP-ZNF580 complexes at different molar ratios of $\mathrm{N} / \mathrm{P}(\mathrm{N} / \mathrm{P}=1,5,10,15,20$; [N/P molar ratios were calculated from weight of polymer and pDNA, N content in the polymer and $\mathrm{P}$ content in pDNA]), the solution was added dropwise into above MPs suspension under stirring. The complexes were allowed to stand for 25-30 minutes at room temperature before characterization.

\section{Size distribution and zeta potential}

The size distribution and zeta potential of MPs and MPs/ pEGFP-ZNF580 complexes were determined using a Zetasizer 3000HS (Malvern Instruments) at the wavelength of $677 \mathrm{~nm}$ with a constant angle of $90^{\circ}$.

\section{Biological characterization}

Agarose gel electrophoresis

Agarose gel electrophoresis was performed as described in a previous work to assess the pEGFP-ZNF580 condensation ability of complex MPs. ${ }^{27}$ Briefly, the MPs/pEGFP-ZNF580 with various N/P molar ratios were formed. Electrophoresis was used to observe the retarded location of DNA.

\section{In vitro cytotoxicity}

The cytotoxicity of MPs and MPs/pEGFP-ZNF580 complexes was determined by MTT assay using PEI $10 \mathrm{kDa}$ as control as reported in previous research..$^{24,27}$ Briefly, EA.hy926 cells (ATCC, Manassas, VA, USA) were seeded in serum-free medium for $12 \mathrm{~h}$. Afterward, the medium was replaced by fresh growth medium. Then, MPs/pEGFP-ZNF580 complexes and MPs solution were added. After $48 \mathrm{~h}$, an enzymelinked immunosorbent assay reader (Titertek Multiscan MC) measured the optical density at the wavelength of $490 \mathrm{~nm}$.

\section{Wound-healing assay}

The migration capability of cells treated with ZNF580 gene was measured as reported previously. ${ }^{24,27,31}$ Cells were transfected at the N/P molar ratio of 20. After $48 \mathrm{~h}$, a "wound" scratch was formed by plastic pipette tip. The migration process was recorded using an inverted microscope. ${ }^{38}$

\section{Transfection in vitro}

EA.hy926 cells were transfected as previously reported. ${ }^{24}$ Before transfection, cells were incubated with serum-free medium for $12 \mathrm{~h}$. The complexes were added into wells. After $4 \mathrm{~h}$, the medium was replaced. The expression of GFP in cells was analyzed.

\section{Results Synthesis of copolymer}

The diblock copolymer mPEG-b-P(MMD-co-LA) was synthesized as shown in Scheme 2. Equipped with a hydrophilic corona, MPs presented high hydrophilicity and flexibility. Cationic copolymer P(MMD-co-LA)-g-PEI was synthesized through the following three steps. First, a hexahydroxylterminated star-shaped copolymer P(MMD-co-LA)-OH was prepared. Then, the star-shaped $\mathrm{P}(\mathrm{MMD}-\mathrm{co}-\mathrm{LA})-\mathrm{COOH}$ was obtained by the reaction between succinic anhydride and $\mathrm{P}(\mathrm{MMD}-\mathrm{co}-\mathrm{LA})-\mathrm{OH}$. Finally, after the amidation reaction between PEI (10 kDa) and P(MMD-co-LA)-COOH, the cationic P(MMD-co-LA)-g-PEI copolymer was formed.

The structure of copolymer was characterized using FT-IR. A peak at $1,096 \mathrm{~cm}^{-1}$ was observed for mPEG-b$\mathrm{P}(\mathrm{MMD}-\mathrm{co}-\mathrm{LA})$ and star-shaped $\mathrm{P}(\mathrm{MMD}-\mathrm{co}-\mathrm{LA})-\mathrm{OH}$ copolymers, which indicated that the ester groups (-O-CO-) existed in P(MMD-co-LA) blocks and mPEG. The absorption peak at $1,753 \mathrm{~cm}^{-1}$ indicated the carboxylate group $(-\mathrm{O}-\mathrm{CO}-)$. The peak at $1691 \mathrm{~cm}^{-1}$ indicated the secondary amide (-NH-) in $\mathrm{P}(\mathrm{MMD}-\mathrm{co}-\mathrm{LA})$. The absorption peak at $2890 \mathrm{~cm}^{-1}$ was assigned to the methylene group $\left(-\mathrm{CH}_{2}-\right)$ in mPEG-b-P(MMD-co-LA) copolymer (Figure 1). ${ }^{3,27}$

The ${ }^{1} \mathrm{H}$ NMR spectra of mPEG-b-P(MMD-co-LA), star-shaped $\mathrm{P}(\mathrm{MMD}-\mathrm{co}-\mathrm{LA})-\mathrm{OH}$, the star-shaped carboxylterminated copolymer $\mathrm{P}(\mathrm{MMD}-\mathrm{co}-\mathrm{LA})-\mathrm{COOH}$ and the cationic copolymer P(MMD-co-LA)-g-PEI are shown in Figure 2. The characteristic peaks of mPEG, LA and MMD residues were assigned as follows: $3.67 \mathrm{ppm}\left(\mathrm{CH}_{2} \mathrm{CH}_{2} \mathrm{O}\right.$ in $\mathrm{mPEG}), 5.18 \mathrm{ppm}\left(\mathrm{OCHCH}_{3} \mathrm{CO}\right.$ in LA residue) and $4.6 \mathrm{ppm}$ ( $\mathrm{COCH}_{2} \mathrm{O}$ in MMD residue). The spectrum of carboxylterminated star-shaped $\mathrm{P}(\mathrm{MMD}$-co-LA)-COOH (Figure 2C) showed a peak at $2.73 \mathrm{ppm}$, which was attributed to the terminal group $\left(\mathrm{COCH}_{2} \mathrm{CH}_{2} \mathrm{COOH}\right)$. Figure $2 \mathrm{D}$ demonstrates characteristic resonances of $\mathrm{NHCH}_{2} \mathrm{CH}_{2}$ protons in PEI at $2.4 \mathrm{ppm}$ to $3.2 \mathrm{ppm} .{ }^{3,29}$ The content of LA and MMD was almost same in P(MMD-co-LA) blocks of mPEG-b-P(MMDco-LA) and star-shaped P(MMD-co-LA)-OH calculated according to ${ }^{1} \mathrm{H}$ NMR. These results suggested that $\mathrm{mPEG}-$ b-P(MMD-co-LA) and cationic P(MMD-co-LA)-g-PEI copolymers were synthesized successfully.

The average molecular weight and the distribution of molecular weight of the synthesized copolymers were determined by GPC (Table 1). The $M_{\mathrm{n}}$ of the copolymer mPEG-b-P(LA-co-MMD) and star-shaped P(MMD-coLA)-OH was calculated to be 14,943 and 20,638 , respectively. The molecular weight distribution of copolymers is shown in Figure 3. 


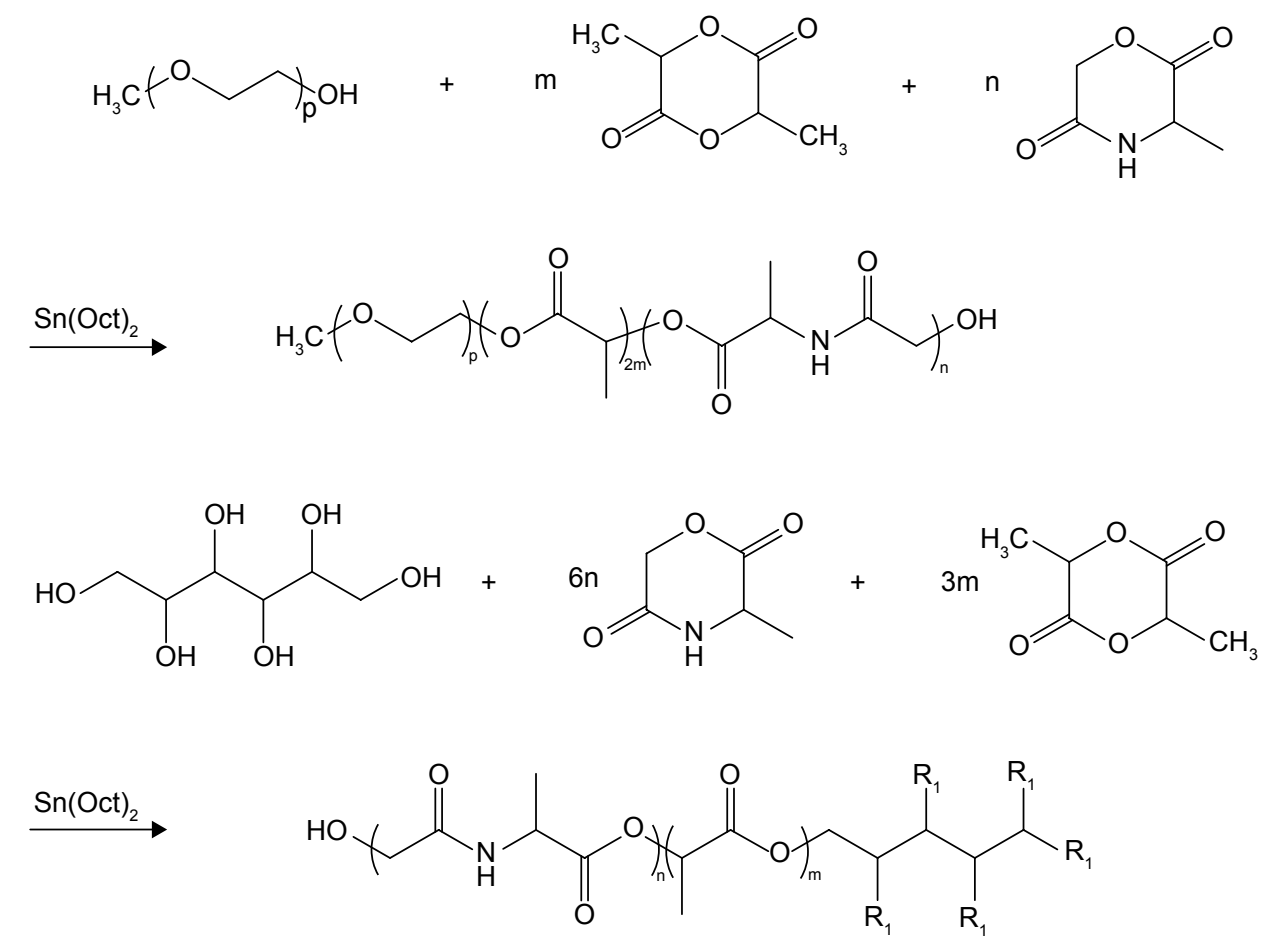<smiles>[R]C([R])C([R])C([R])C([R])COC(=O)C(C)(C)OC(=O)C(C)NC(=O)COC(=O)CCC(=O)O</smiles><smiles>[R]C([R])C([R])C([R])C([R])CC(C)OC(=O)C(C)OC(=O)C(C)NC(=O)COC(=O)CCC(=O)C=[Pt]</smiles>

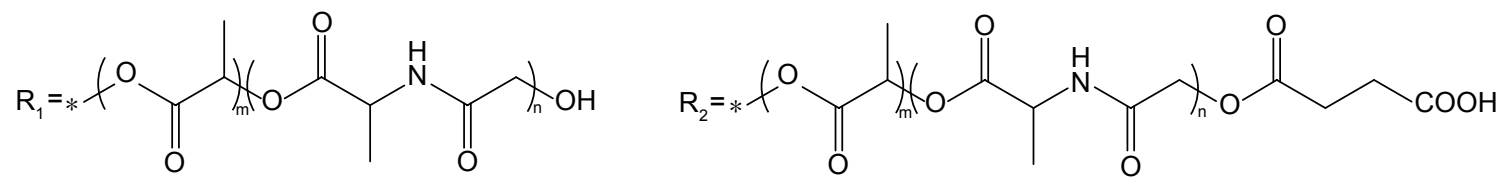

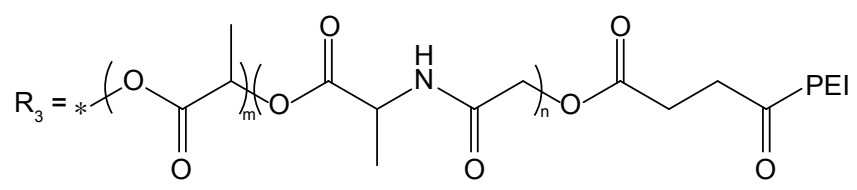

Scheme 2 Synthesis of diblock copolymer mPEG-b-P(MMD-co-LA) and cationic copolymer P(MMD-co-LA)-g-PEl.

Abbreviations: mPEG, methoxy-poly(ethylene glycol); P(MMD-co-LA), poly(3(S)-methyl-morpholine-2,5-dione-co-lactide); PEl, polyethylenimine; Sn(Oct), stannous octoate; DMAP, 4-dimethylamino pyridine; EDC, I-ethyl-3-(3-dimethylaminopropyl)-carbodiimide hydrochloride; NHS, N-hydroxy succinimide; DMSO, dimethyl sulfoxide. 


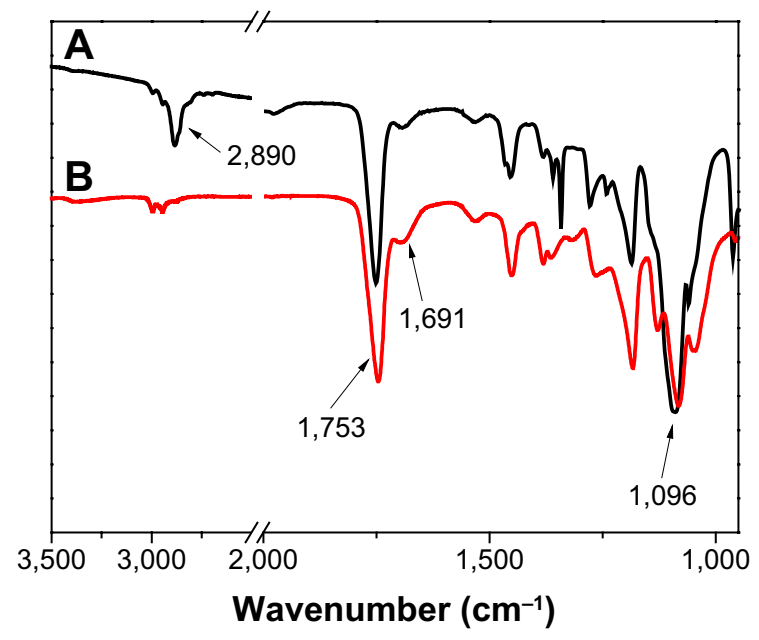

Figure I FT-IR spectra (A: copolymer mPEG-b-P(MMD-co-LA); B: star-shaped $\mathrm{P}(\mathrm{MMD}-\mathrm{co}-\mathrm{LA})-\mathrm{OH})$.

Abbreviations: FT-IR, Fourier transform infrared; mPEG, methoxy-poly(ethylene glycol); P(MMD-co-LA), poly(3(S)-methyl-morpholine-2,5-dione-co-lactide).

\section{Zeta potential and hydrodynamic diameter of MPs and MPs/pEGFP- ZNF580 complexes}

The size and zeta potential are important parameters that affect endocytosis. The particle size is an important factor for cellular uptake. ${ }^{39}$ MPs with suitable diameter (below $200 \mathrm{~nm}$ ) are much easily endocytosed and are less impressionable to be cleared by the reticuloendothelial system. ${ }^{29}$ The positive-charged surface is more favorable for endocytosis. The co-self-assembly of copolymer mPEG-b-P(MMDco-LA) and cationic copolymer P(MMD-co-LA)-g-PEI at different mass ratios could lead to form MPs with P(MMDco-LA) core and mixed mPEG/PEI shell. Three kinds of MPs were prepared from mPEG-b-P(MMD-co-LA) and cationic copolymer P(MMD-co-LA)-g-PEI. The mass ratios
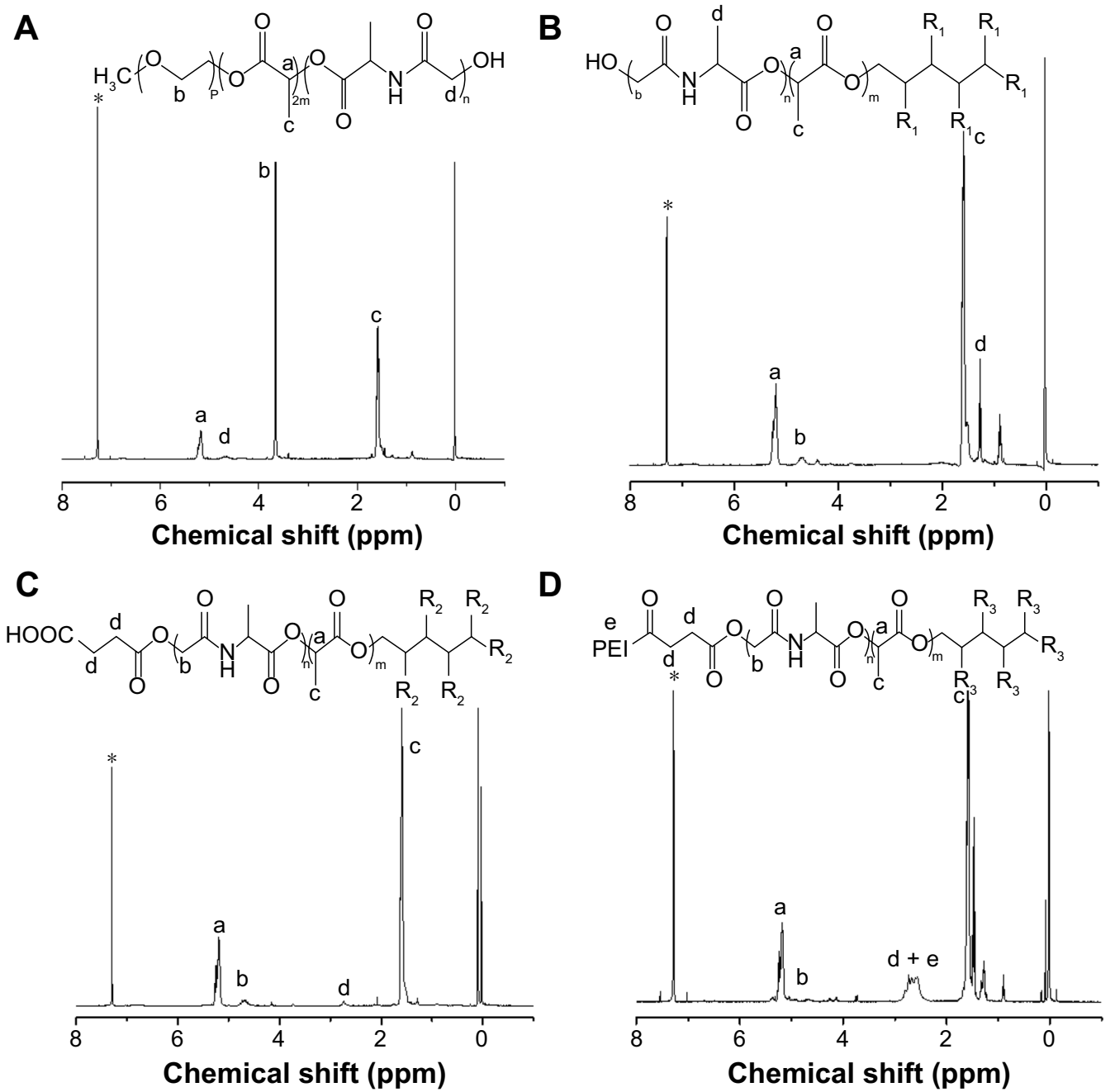

Figure 2 'H NMR spectra of copolymers.

Notes: (A) mPEG-b-P(MMD-co-LA). (B) Star-shaped P(MMD-co-LA)-OH. (C) Star-shaped P(MMD-co-LA)-COOH. (D) P(MMD-co-LA)-g-PEl. *CDCl ${ }_{3}$ peaks. In Figure 2C, a: peak at $5.18 \mathrm{ppm}$ attribute to $\left(-\mathrm{OCHCH}_{3} \mathrm{CO}-, \mathrm{IH}\right)$ in LA residue; b: peak at $4.6 \mathrm{ppm}$ attribute to $\left(-\mathrm{COCH}_{2} \mathrm{O}-, 2 \mathrm{H}\right)$ in $\mathrm{MMD}$ residue; c: peak at I.59 Ppm attribute to $\left(-\mathrm{COCH}\left(\mathrm{CH}_{3}\right) \mathrm{O}-, 3 \mathrm{H}\right)$ in $\mathrm{LA}$ residue; d: peak at $2.73 \mathrm{ppm}$ attributed to $\left(-\mathrm{COCH}_{2} \mathrm{CH}_{2} \mathrm{COOH}, 4 \mathrm{H}\right)$, the terminal group of $\mathrm{P}(\mathrm{MMD}-\mathrm{co}-\mathrm{LA})-\mathrm{COOH}$.

Abbreviations: 'H-NMR, proton nuclear magnetic resonance; mPEG, methoxy-poly(ethylene glycol); P(MMD-co-LA), poly(3(S)-methyl-morpholine-2,5-dione-co-lactide); $\mathrm{PEI}$, polyethylenimine. 
Table I Characterization of diblock copolymer mPEG-b-P(MMDco-LA) and star-shaped copolymer P(MMD-co-LA)-OH

\begin{tabular}{llllll}
\hline Sample ID & $\boldsymbol{F}_{\text {LA }}{ }^{a}(\%)$ & $\boldsymbol{M}_{\mathrm{n}}{ }^{\mathrm{b}}$ & $\boldsymbol{M}_{\mathrm{n}}{ }^{\mathrm{c}}$ & $\boldsymbol{M}_{\mathrm{w}}{ }^{\mathrm{c}}$ & PDI $^{\mathrm{c}}$ \\
\hline mPEG-b-P(MMD-co-LA) & 90.4 & 12,200 & 14,943 & 24,508 & $1.640 \mathrm{I}$ \\
P(MMD-co-LA)-OH & 91.1 & - & 20,638 & 37,455 & 1.8148
\end{tabular}

Notes: aWeight content of LA in P(MMD-co-LA) block, calculated from 'H NMR spectroscopy. ${ }^{\text {bC }}$ alculated according to 'H NMR. 'Determined by means of GPC using THF as eluent and polystyrene standards for calibration.

Abbreviations: mPEG, methoxy-poly(ethylene glycol); P(MMD-co-LA), poly(3(S)methyl-morpholine-2,5-dione-co-lactide); $M_{n}$, number-average molecular weight; $M_{w}$, weight-average molecular weight; PDI, polydispersity index; LA, lactide; 'H NMR, proton nuclear magnetic resonance; GPC, gel permeation chromatography; THF, tetrahydrofuran.

of mPEG-b-P(MMD-co-LA) to P(MMD-co-LA)-g-PEI were $3 / 1,2 / 2$ and $1 / 3$. Complexes were prepared by mixing the MPs suspension and pEGFP-ZNF580 in PBS to form the MPs/pEGFP-ZNF580 complexes.

As shown in Figure 4, the hydrodynamic diameter $\left(D_{\mathrm{h}}\right)$ was measured by dynamic light scattering (DLS). The $D_{\mathrm{h}}$ values of these three kinds of MPs were $83.7 \pm 0.3 \mathrm{~nm}$, $83.1 \pm 5.4 \mathrm{~nm}$ and $82.5 \pm 6.5 \mathrm{~nm}$, respectively. In addition, the size of MPs/pEGFP-ZNF580 complexes was affected by the $\mathrm{N} / \mathrm{P}$ ratio. When the mass ratio of $\mathrm{mPEG}-\mathrm{b}-\mathrm{P}(\mathrm{MMD}-\mathrm{co}-\mathrm{LA})$ to $\mathrm{P}(\mathrm{MMD}$-co-LA)-g-PEI was 3:1, the increasing size of MPs/pEGFP-ZNF580 at N/P molar ratio of 5 was mainly due to the introduction of plasmid, while the reducing trend of size at higher N/P ratios may result from better plasmidcondensing effect and more compact structure of the complexes compared with that at $\mathrm{N} / \mathrm{P}=5 .^{40}$ The complexes with other mass ratios (2:2 and 1:3) of mPEG-b-P(MMD-co-LA) to $\mathrm{P}(\mathrm{MMD}-\mathrm{co}-\mathrm{LA})$-g-PEI also showed the same tendency. More importantly, all of the MPs and the complexes were less than $120 \mathrm{~nm}$ and beneficial for endocytosis.

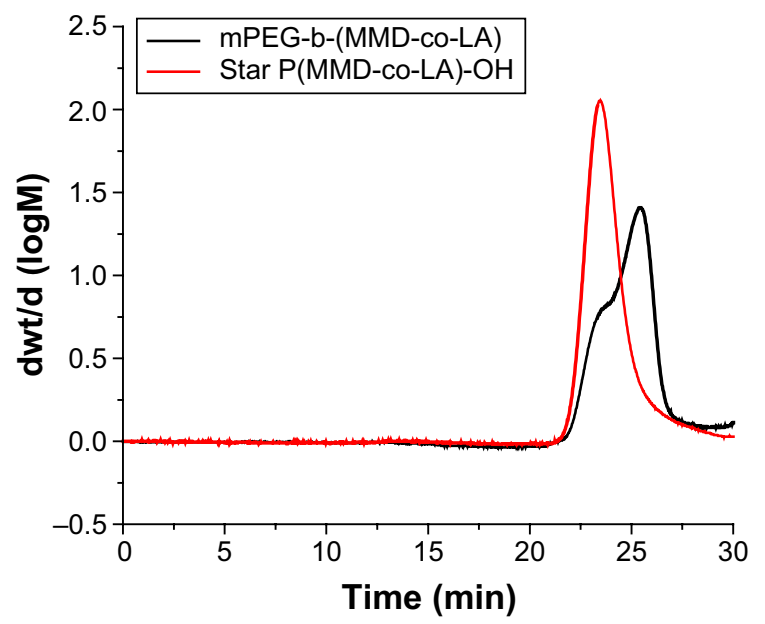

Figure 3 GPC traces of diblock copolymer mPEG-b-P(MMD-co-LA) and starshaped $\mathrm{P}(\mathrm{MMD}-\mathrm{CO}-\mathrm{LA})-\mathrm{OH}$.

Abbreviations: GPC, gel permeation chromatography; mPEG, methoxy-poly(ethylene glycol); P(MMD-co-LA), poly(3(S)-methyl-morpholine-2,5-dione-co-lactide).
As shown in Figure 4, the MPs possessed positive charge because the grafted cationic PEI maintained relatively high zeta potential. With the increasing PEI content in shell (the mass ratios of mPEG-b-P(MMD-co-LA) to P(MMD-co-LA)g-PEI from $3 / 1$ to $1 / 3$ ), the zeta potential of MPs increased from $19.6 \pm 4.2 \mathrm{mV}$ to $24.0 \pm 0.6 \mathrm{mV}$. When the ratios of mPEG-b-P(MMD-co-LA) to P(MMD-co-LA)-g-PEI were same, the zeta potential of the complexes increased with the increasing molar ratio of $\mathrm{N} / \mathrm{P}$. These results indicated that the MPs/pEGFP-ZNF580 complexes may be suitable for cell adhesion, cell uptake and transfection. ${ }^{41}$

\section{Agarose gel electrophoresis}

Through electrostatic interaction, well-designed gene carriers can effectively condense negatively charged pEGFP-ZNF580 into MPs. ${ }^{42}$ In the present investigation, agarose gel electrophoresis assays were performed to confirm the successful binding between MPs and pEGFP-ZNF580.

As shown in Figure 5, the MPs/pEGFP-ZNF580 complexes could condense pEGFP-ZNF580 efficiently by changing N/P molar ratio. MPs with $3 / 1,2 / 2$ and $1 / 3$ ratios of mPEG-b-P(MMD-co-LA) to P(MMD-co-LA)-g-PEI could retard the $\mathrm{pEGFP}-\mathrm{ZNF} 580$ migration at $\mathrm{N} / \mathrm{P}$ ratios of 15,15 and 10 , respectively. This tendency can be explained by that gene carriers help in efficient condensation of pEGFPZNF580 with high positive potential. Furthermore, when the content of PEI in the mixed shell increased, the condensation ability of MPs was enhanced gradually. However, when the content of mPEG in the mixed shell was high, pEGFPZNF580 could not be bound totally.

\section{In vitro cytotoxicity}

The cytotoxicity of MPs and MPs/pEGFP-ZNF580 complexes was evaluated. The concentration ranged from 10 to $100 \mathrm{mg} \mathrm{L}^{-1}$. After $24 \mathrm{~h}$, the relative viability of cells treated with the complexes was measured. Results showed that relative cell viability of MPs/pEGFP-ZNF580 complexes and MPs was much higher than high-molecular weight PEI at the same concentration (Figure 6). The cytotoxicity of MPs/pEGFPZNF580 complexes was lower after loading ZNF580 at the same concentration. This phenomenon could be attributed to the surface positive charge density, which reflected the cell compatibility of these polycationic MPs. High positive charges on the surface of MPs usually result in the death of cells. ${ }^{43}$ At the same concentration, the cell viability presented a descending trend of MPs/pEGFP-ZNF580 complexes gradually along with the decrease in mass ratios of $\mathrm{mPEG}-\mathrm{b}-\mathrm{P}(\mathrm{MMD}-\mathrm{co}-\mathrm{LA})$ to $\mathrm{P}(\mathrm{MMD}-\mathrm{co}-\mathrm{LA})$-g-PEI from $3 / 1$ to $0 / 4$. For example, the cell 

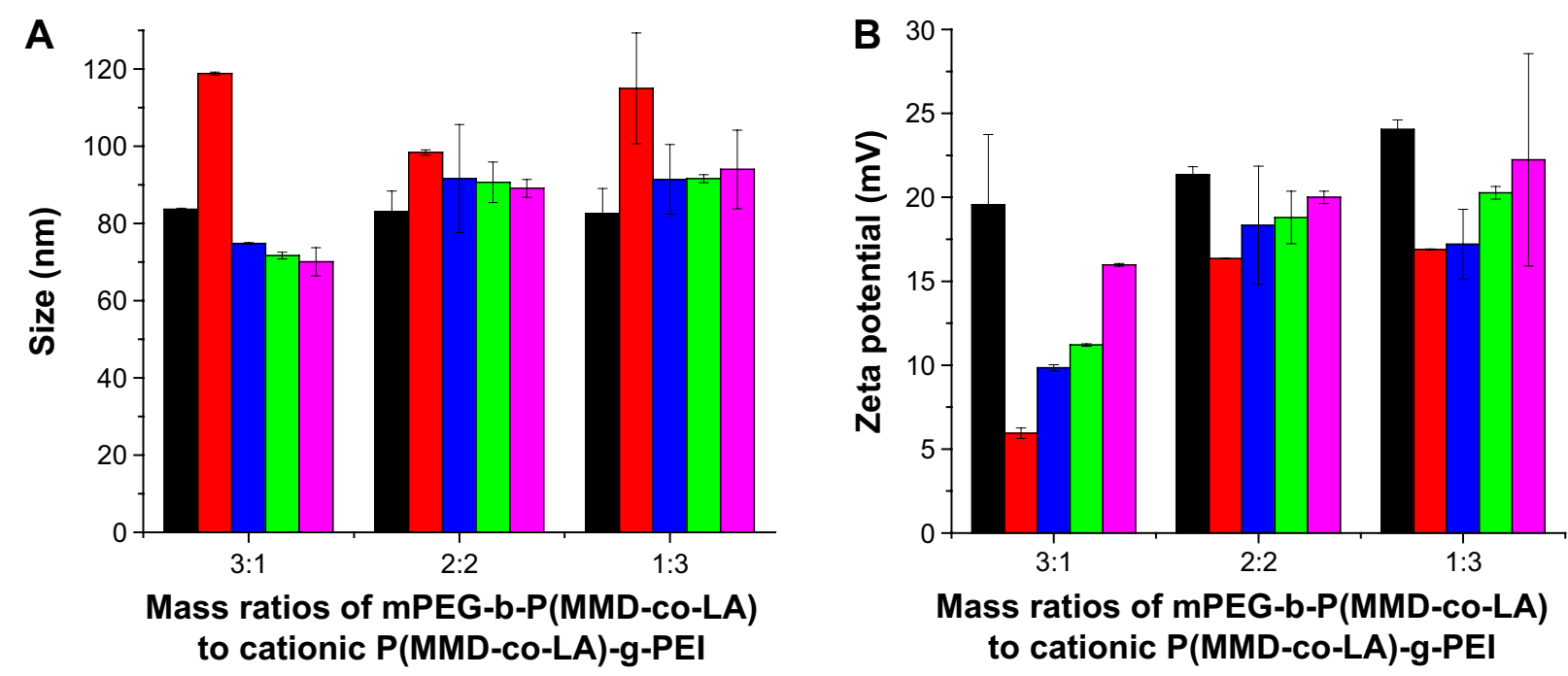

$\square$ Blank $\square$ N/P =5 $\square$ N/P =10 $\square$ N/P =15 $\square$ N/P =20

Figure 4 Hydrodynamic diameter $\left(D_{h}\right)$ and zeta potential of MPs and MPs/pEGFP-ZNF580 complexes measured by DLS.

Notes: $(\mathbf{A})$ Hydrodynamic diameter $\left(D_{h}\right)$. (B) Zeta potential by DLS. N/P molar ratios were calculated from weight of polymer and pDNA, N content in the polymer and $P$ content in PDNA.

Abbreviations: MPs, microparticles; DLS, dynamic light scattering; mPEG, methoxy-poly(ethylene glycol); P(MMD-co-LA), poly(3(S)-methyl-morpholine-2,5-dione-colactide); PEl, polyethylenimine.

viability of MPs/pEGFP-ZNF580 complexes $\left(60 \mu \mathrm{g} \mathrm{mL} \mathrm{mL}^{-1}\right)$ with the $3 / 1,2 / 2,1 / 3$ and $0 / 4$ mass ratios was $78.5 \% \pm 0.4 \%$, $72.6 \% \pm 0.4 \%, 72.5 \% \pm 0.2 \%$ and $53.9 \% \pm 0.2 \%$, respectively. The main reason could be as follows: when the N/P was same, the zeta potential of MPs/pEGFP-ZNF580 complexes was improved as the content of positively charged PEI increased. High positive charges could be fatal to the cells. The chains of PEG could shield PEI and buffer the adsorption of polymers and cell membrane. ${ }^{28}$ The increased PEG content enhanced the shielding effect greatly, thus decreasing the cytotoxicity. When the concentration was below $30 \mu \mathrm{g} \mathrm{mL}^{-1}$, MPs and complexes showed perfect cell viability. The corresponding value of the relative cell viability was above $75 \%$. These results manifested that the concentration of $30 \mu \mathrm{g} \mathrm{mL}^{-1}$ was the suitable standard for the MPs/pEGFP-ZNF580 complexes system used as lowcytotoxic gene carriers.

\section{Cell migration}

The migration and proliferation of different cell lines were evaluated via the scratch assay. ${ }^{44}$ It is a relatively simple and straightforward approach for analyzing cell migration in vitro. ${ }^{45}$ In the present study, an artificial scratch with parallel borders was mechanically created as shown in Figure 7. The cells migrated to close this "wound" scratch
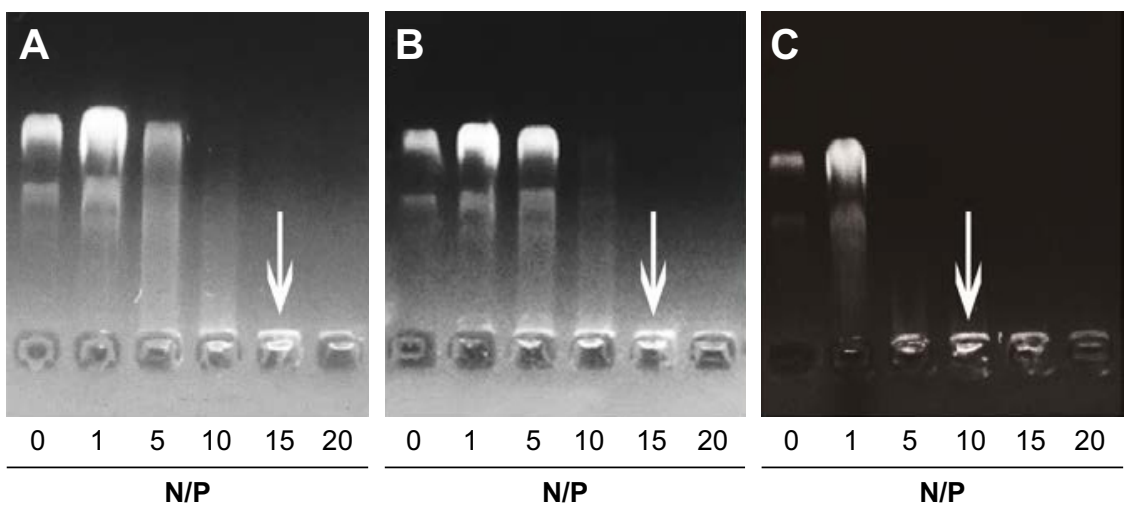

Figure 5 Agarose gel electrophoresis of MPs/pEGFP-ZNF580 complexes at various N/P ratios (0, I, 5, 10, I5 and 20).

Notes: MPs and MPs/pEGFP-ZNF580 complexes at various N/P ratios (0, 1, 5, 10, 15 and 20). (A) MPs/pEGFP-ZNF580 complexes were prepared from MPs with 3/I mass ratio of mPEG-b-P(MMD-co-LA) to P(MMD-co-LA)-g-PEl at various N/P ratios. (B) MPs/pEGFP-ZNF580 complexes were prepared from MPs with $2 / 2$ mass ratio of mPEG-b$\mathrm{P}(\mathrm{MMD}$-co-LA) to $\mathrm{P}(\mathrm{MMD}$-co-LA)-g-PEl at various N/P ratios. (C) MPs/pEGFP-ZNF580 complexes were prepared from MPs with I/3 mass ratio of mPEG-b-P(MMD-co-LA) to $\mathrm{P}(\mathrm{MMD}$-co-LA)-g-PEl at various N/P ratios. The arrows indicate the N/P ratios where the DNA mobility is completely retarded. N/P molar ratios were calculated from weight of polymer and PDNA, $\mathrm{N}$ content in the polymer and $\mathrm{P}$ content in PDNA.

Abbreviations: MPs, microparticles; mPEG, methoxy-poly(ethylene glycol); P(MMD-co-LA), poly(3(S)-methyl-morpholine-2,5-dione-co-lactide); PEl, polyethylenimine. 

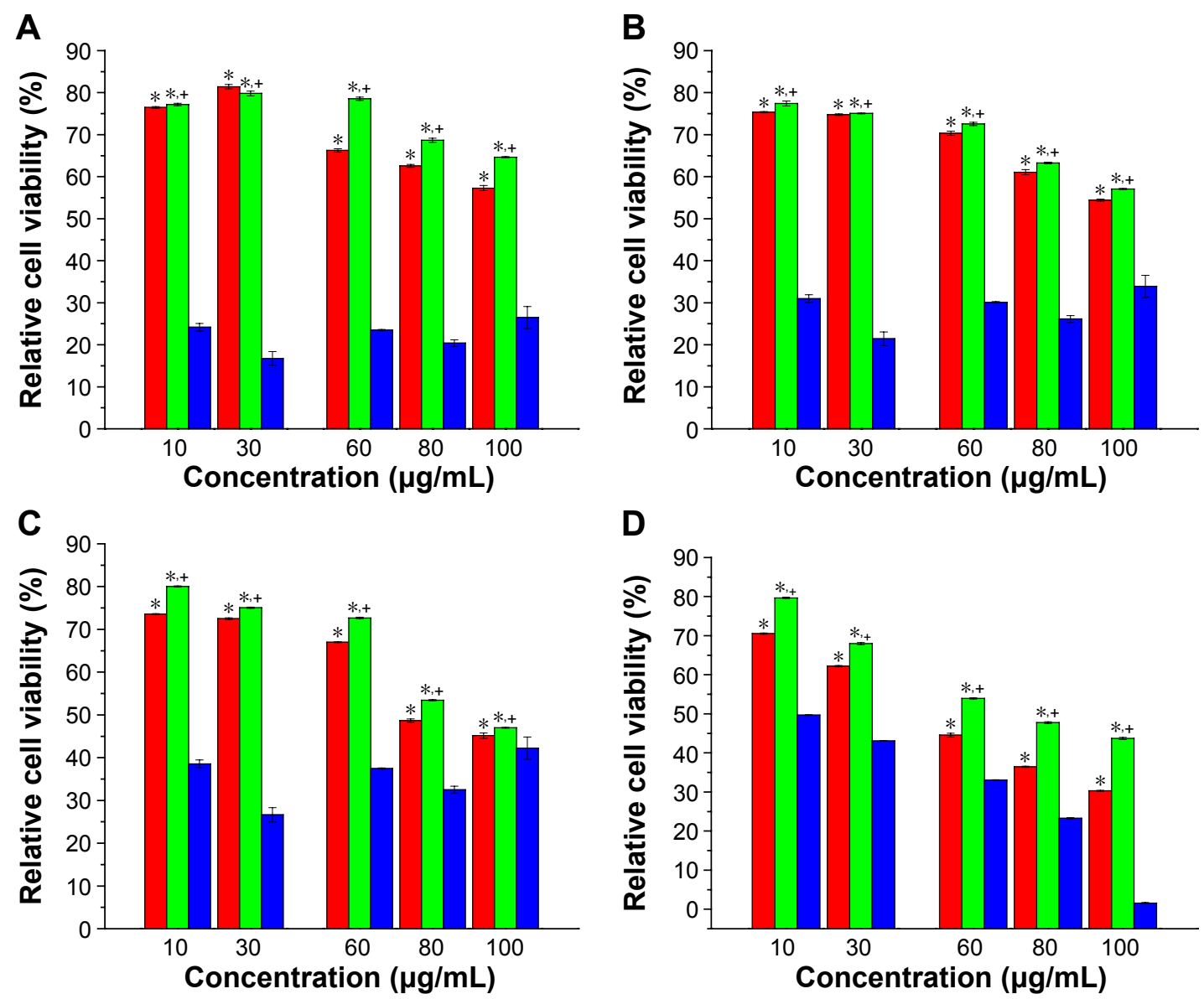

$\square$ MPs $\square$ MPs/pEGFP-ZNF580 complexes $\square$ PEI 10K

Figure 6 Relative cell viability of EA.hy926 cells with different concentrations of MPs and MPs/pEGFP-ZNF580 complexes at N/P molar ratio of 20.

Notes: Cells treated with PEI $\left(M_{w}=10 \mathrm{kDa}\right.$ ) served as the control group. (A) 3/I mass ratio of mPEG-b-P(MMD-co-LA) to P(MMD-co-LA)-g-PEl. (B) 2/2 mass ratio of mPEG-b-P(MMD-co-LA) to P(MMD-co-LA)-g-PEI. (C) I/3 mass ratio of mPEG-b-P(MMD-co-LA) to P(MMD-co-LA)-g-PEI. (D) 0/4 mass ratio of mPEG-b-P(MMD-co-LA) to $\mathrm{P}\left(\mathrm{MMD}\right.$-co-LA)-g-PEI. ( \pm SD, $n=3, * P<0.05$ as compared with the $\mathrm{PEI} 10 \mathrm{k}$ group; ${ }^{+} \mathrm{P}<0.05$ as compared with the MPs group).

Abbreviations: MPs, microparticles; PEI, polyethylenimine; $M_{w}$, weight-average molecular weight; mPEG, methoxy-poly(ethylene glycol); P(MMD-co-LA), poly(3(S)-methylmorpholine-2,5-dione-co-lactide); SD, standard deviation.

after cells treated with MPs/pEGFP-ZNF580 complexes which were prepared from 3/1, 2/2 and 1/3 ratios of $\mathrm{mPEG-}$ b-P(MMD-co-LA) to P(MMD-co-LA)-g-PEI.

Compared with cells without any treatment, cells treated with MPs/pEGFP-ZNF580 complexes showed a high migration rate (more than $90 \%$ ). The migration rate of cells treated with complexes with the $3 / 1,2 / 2$ and $1 / 3$ ratios of mPEG-b-P(MMD-co-LA) to P(MMD-co-LA)-g-PEI was slightly higher than the group treated with the complex with the ratio of $0 / 4$. This phenomenon is mainly due to the high cytotoxicity of the complexes with ratio of $0 / 4$. The $2 / 2$ and $1 / 3$ ratio groups showed relatively high cell migration.

\section{In vitro transfection}

The pEGFP-ZNF580 could be transported into EA.hy926 cells by MP gene carriers. After escaping from lysosome,
pEGFP-ZNF580 entered into the nucleus, and expressed effectively. In order to determine qualitatively whether the pEGFP-ZNF580 had been transfected into the EA.hy926 cells, the expression of GFP in ECs was observed under the fluorescent microscope. The concentration of MPs/pEGFPZNF580 complexes suspension was $30 \mu \mathrm{g} \mathrm{mL}^{-1}(\mathrm{~N} / \mathrm{P}=20)$. Both cells treated with pEGFP-ZNF580 and complexes with 0/4 ratio of mPEG-b-P(MMD-co-LA) to P(MMD-co-LA)g-PEI served as the control groups.

As shown in Figure 8, cells labeled with green fluorescence were observed obviously in test groups, which indicated that the plasmids had transfected and expressed successfully in cells. Furthermore, the MPs/pEGFP-ZNF580 complexes with $1 / 3$ mass ratio of $\mathrm{mPEG}-\mathrm{b}-\mathrm{P}(\mathrm{MMD}-\mathrm{co}-\mathrm{LA})$ to $\mathrm{P}(\mathrm{MMD}$ co-LA)-g-PEI showed high transfection efficiency. This phenomenon could be attributed to the high positive charge 
$1 \mathrm{~A}$

$\mathbf{O h}$

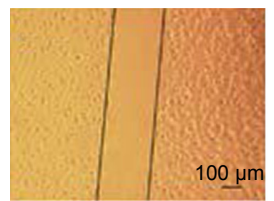

$12 \mathrm{~h}$

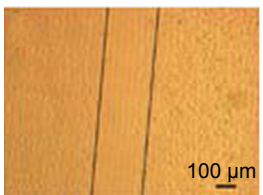

$24 \mathrm{~h}$

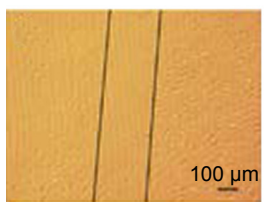

B
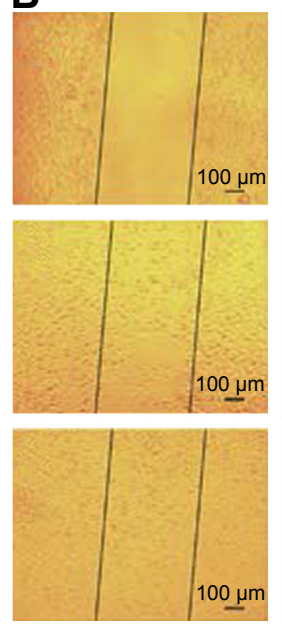

C
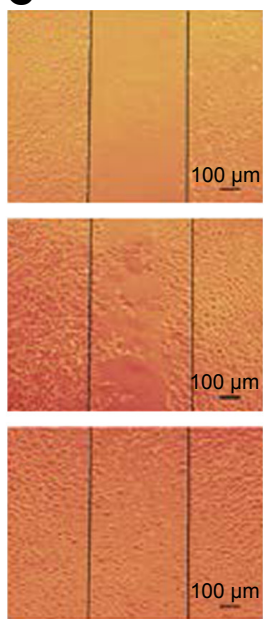

D
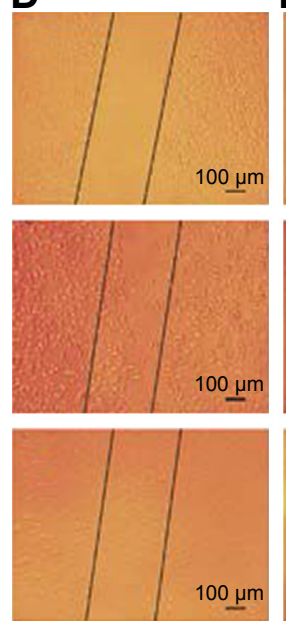

E
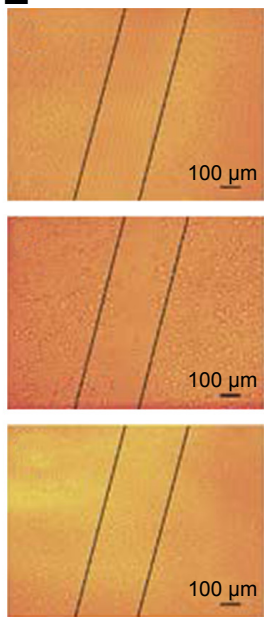

2

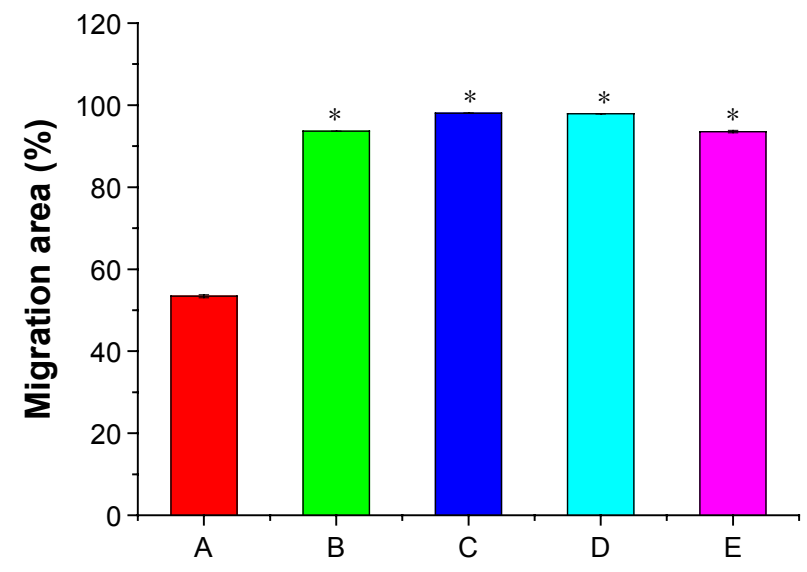

Figure 7 Migration process of transfected EA.hy926 cells by MPs/pEGFP-ZNF580 complexes at N/P molar ratio of 20 at different (I) time points and (2) migration area after $24 \mathrm{~h}$ calculated by Image-Pro Plus (version 6.0).

Notes: Cells without any treatment served as the control. (A) Cells without any treatment. (B) Cells treated with MPs/pEGFP-ZNF580 complexes which were prepared from MPs with $3 / 1$ mass ratio of mPEG-b-P(MMD-co-LA) to P(MMD-co-LA)-g-PEl. (C) Cells treated with MPs/pEGFP-ZNF580 complexes which were prepared from MPs with 2/2 mass ratio of mPEG-b-P(MMD-co-LA) to P(MMD-co-LA)-g-PEl. (D) Cells treated with MPs/pEGFP-ZNF580 complexes which were prepared from MPs with I/3 mass ratio of mPEG-b-P(MMD-co-LA) to P(MMD-co-LA)-g-PEI. (E) Cells treated with MPs/pEGFP-ZNF580 complexes which were prepared from MPs with 0/4 mass ratio of mPEG-b-P(MMD-co-LA) to $P(M M D-c o-L A)-g-P E I ~( \pm S D, n=3, * P<0.05$ vs control group).

Abbreviations: MPs, microparticles; mPEG, methoxy-poly(ethylene glycol); P(MMD-co-LA), poly(3(S)-methyl-morpholine-2,5-dione-co-lactide); PEI, polyethylenimine; SD, standard deviation.

A

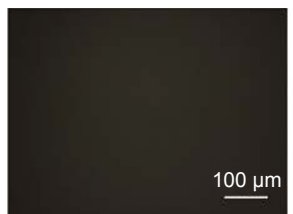

$24 \mathrm{~h}$

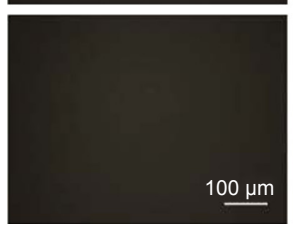

B
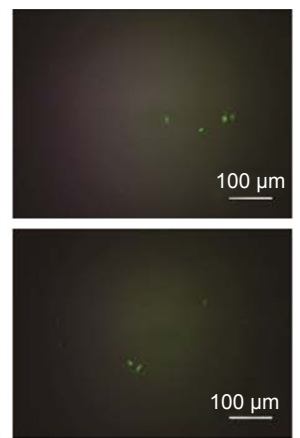

C
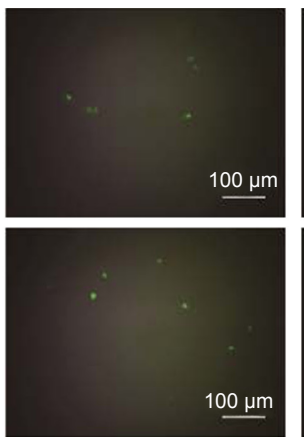

D
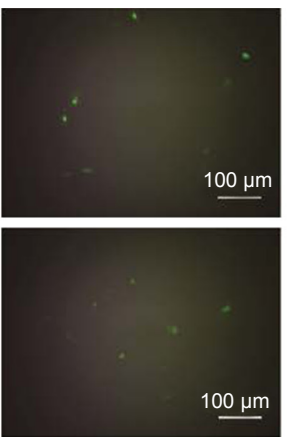

$\mathbf{E}$

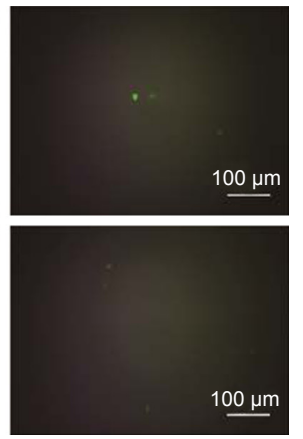

Figure 8 Fluorescence images of EA.hy926 cells transfected by complexes at different ratios of mPEG-b-P(MMD-co-LA) to P(MMD-co-LA)-g-PEl at the N/P molar ratio of 20 and time intervals of 12 and $24 \mathrm{~h}$.

Notes: (A) Cells treated with pEGFP-ZNF580. (B) Cells treated with MPs/pEGFP-ZNF580 complexes which were prepared from 3/I mass ratio of mPEG-b-P(MMD-coLA) to P(MMD-co-LA)-g-PEl. (C) Cells treated with MPs/pEGFP-ZNF580 complexes which were prepared from 2/2 mass ratio of mPEG-b-P(MMD-co-LA) to P(MMD-coLA)-g-PEl. (D) Cells treated with MPs/pEGFP-ZNF580 complexes which were prepared from I/3 mass ratio of mPEG-b-P(MMD-co-LA) to P(MMD-co-LA)-g-PEI. (E) Cells treated with MPs/pEGFP-ZNF580 complexes which were prepared from 0/4 mass ratio of mPEG-b-P(MMD-co-LA) to P(MMD-co-LA)-g-PEl.

Abbreviations: mPEG, methoxy-poly(ethylene glycol); P(MMD-co-LA), poly(3(S)-methyl-morpholine-2,5-dione-co-lactide); PEI, polyethylenimine; MPs, microparticles. 
density of PEI, which had unique proton sponge effect without additional disruptive reagents of endosome. ${ }^{46-49}$

\section{Discussion}

To obtain gene carriers with good transfection efficiency and less cytotoxicity for the proliferation of ECs, amphiphilic copolymers P(MMD-co-LA)-g-PEI and mPEG-b-P(MMDco-LA) were prepared in the present study. To increase the transfection efficiency, PEI with low molecular weight was grafted onto the end of star-shaped copolymer P(MMD-coLA)-COOH, which has the dense molecular architecture and flexible tailored structure. The MPs consisting of a P(MMDco-LA) core and a mixed mPEG/PEI shell could be formed by co-self-assembly, in which the hydrophilic mPEG preferentially stretches at the outmost surface of the MPs. It can shield PEI to decrease its cytotoxicity and increase the circulation time and stability in the shell of gene delivery micelles. ${ }^{50}$ The pEGFP-ZNF580 could be condensed and loaded by these MPs to form complexes. In the present study, to testify whether the different $\mathrm{mPEG} / \mathrm{PEI}$ ratios of complexes influence the transfection efficiency of complexes dramatically or not, a series of MPs consisting of different mass ratios of mPEG-b-P(MMDco-LA) to P(MMD-co-LA)-g-PEI were prepared.

The results of gel electrophoresis showed that MPs could condense and load pEGFP-ZNF580 efficiently by changing $\mathrm{N} / \mathrm{P}$ molar ratios. The cytotoxicity of gene carriers demonstrated that these shielded gene transfer systems have lower cytotoxicity and prolong circulation times in vivo. Due to the shielding effect of PEG, when the mass ratio of mPEG-b$\mathrm{P}(\mathrm{MMD}-\mathrm{co}-\mathrm{LA})$ to $\mathrm{P}$ (MMD-co-LA)-g-PEI was 3/1, the MPs co-self-assembled by these two kinds of copolymers showed the lowest cytotoxicity. Moreover, the special structure of MPs could also contribute to reduce the cytotoxicity of MPs/ pEGFP-ZNF580 complexes.

The transfection efficiency of MPs/pEGFP-ZNF580 complexes was further evaluated. With the increasing content of PEI, the transfection of ECs could be improved gradually. The star-shaped structure of P(MMD-co-LA) carries high content of PEI which helps to enhance transfection efficiency, through which the endocytosis could be improved. These results showed that gene carrier with $1 / 3$ ratio of mPEG-b-P(MMD-co-LA) to P(MMD-co-LA)-g-PEI was the most suitable for gene transfection among the groups. Furthermore, because of the low cytotoxicity, the transfection efficiency of complexes with $3 / 1,2 / 2$ and $1 / 3$ ratios was higher than the complexes with $0 / 4$ ratio of $\mathrm{mPEG}$ b-P(MMD-co-LA) to P(MMD-co-LA)-g-PEI. In addition, the migration of ECs treated with MPs/pEGFP-ZNF580 complexes was much better than untreated cells, and the difference between three kinds of complexes was not obvious. According to the above results, the gene carriers formed via co-self-assembly had low cytotoxicity and high transfection efficiency and enhanced the property of cell migration and proliferation.

\section{Conclusion}

We synthesized a cationic copolymer P(MMD-co-LA)-gPEI and a diblock copolymer mPEG-b-P(MMD-co-LA). A series of MPs with suitable diameter and positive charge were prepared. pEGFP-ZNF580 was effectively delivered into ECs by these MP complexes. The MPs as gene carriers exhibited low cytotoxicity and facilitated enhanced proliferation as well as improved migration of ECs. This kind of gene carrier might have great application for modifying artificial blood vessels in order to accomplish endothelialization.

\section{Acknowledgments}

This project was supported by the State Key Project of Research and Development (Grant No 2016YFC1100300), the National Natural Science Foundation of China (Grant No 31370969 and 51673145), the International Science \& Technology Cooperation Program of China (Grant No 2013DFG52040), the Natural Science Foundation of Tianjin and Youth Science Foundation (Grant No 14JCQNJC02900), the $\mathrm{PhD}$ Programs Foundation of Ministry of Education of China (No 20120032110073), the Program of Introducing Talents of Discipline to Universities of China (No B06006) and Wenzhou government's startup fund (Grant No WIBEZD2014005-03 and WIBEZD2015009-03), Wenzhou Science and Technology Bureau (Y20150088).

\section{Disclosure}

The authors report no conflicts of interest in this work.

\section{References}

1. Wennerholm C, Grip B, Johansson A, Nilsson H, Honkasalo ML, Faresjo T. Cardiovascular disease occurrence in two close but different social environments. Int J Health Geogr. 2011;10:5.

2. Ren X, Feng Y, Guo J, et al. Surface modification and endothelialization of biomaterials as potential scaffolds for vascular tissue engineering applications. Chem Soc Rev. 2015;44:5680-5742.

3. Shi C, Yao F, Li Q, et al. Regulation of the endothelialization by human vascular endothelial cells by ZNF580 gene complexed with biodegradable microparticles. Biomaterials. 2014;35(25):7133-7145.

4. Wang Y, Zhang W, Zhang J, Sun W, Zhang R, Gu H. Fabrication of a novel polymer-free nanostructured drug-eluting coating for cardiovascular stents. ACS Appl Mater Interfaces. 2013;5(20):10337-10345.

5. Feng Y, Zhao H, Behl M, Lendlein A, Guo J, Yang D. Grafting of poly(ethylene glycol) monoacrylates on polycarbonateurethane by UV initiated polymerization for improving hemocompatibility. J Mater Sci Mater Med. 2013;24(1):61-70. 
6. Wang H, Feng Y, Fang Z, Xiao R, Yuan W, Khan M. Fabrication and characterization of electrospun gelatin-heparin nanofibers as vascular tissue engineering. Macromol Res. 2013;21(8):860-869.

7. Yang J, Lv J, Gao B, et al. Modification of polycarbonateurethane surface with poly (ethylene glycol) monoacrylate and phosphorylcholine glyceraldehyde for anti-platelet adhesion. Front Chem Sci Eng. 2014; 8(2):188-196.

8. Yuan W, Feng Y, Wang H, et al. Hemocompatible surface of electrospun nanofibrous scaffolds by ATRP modification. Mater Sci Eng C Mater Biol Appl. 2013;33(7):3644-3651.

9. Wang H, Feng Y, Fang Z, Yuan W, Khan M. Co-electrospun blends of $P U$ and $P E G$ as potential biocompatible scaffolds for small-diameter vascular tissue engineering. Mater Sci Eng C. 2012;32(8):2306-2315.

10. Yang J, Lv J, Behl M, et al. Functionalization of polycarbonate surfaces by grafting PEG and zwitterionic polymers with a multicomb structure. Macromol Biosci. 2013;13(12):1681-1688.

11. Wang H, Feng Y, An B, et al. Fabrication of PU/PEGMA crosslinked hybrid scaffolds by in situ UV photopolymerization favoring human endothelial cells growth for vascular tissue engineering. J Mater Sci Mater Med. 2012;23(6):1499-1510.

12. Wang H, Feng Y, Zhao H, et al. Controlled heparin release from electrospun gelatin fibers. J Control Release. 2011;152 Suppl 1:e28-e29.

13. Gao B, Feng Y, Lu J, et al. Grafting of phosphorylcholine functional groups on polycarbonate urethane surface for resisting platelet adhesion. Mater Sci Eng C Mater Biol Appl. 2013;33(5):2871-2878.

14. Lu J, Feng Y, Gao B, Guo J. Grafting of a novel phosphorylcholinecontaining vinyl monomer onto poly-carbonateurethane surfaces by ultraviolet radiation grafting polymerization. Macromol Res. 2012;20(7):693-702.

15. Zhu Y, Gao C, He T, Shen J. Endothelium regeneration on luminal surface of polyurethane vascular scaffold modified with diamine and covalently grafted with gelatin. Biomaterials. 2004;25(3):423-430.

16. Mattix BM, Olsen TR, Casco M, et al. Janus magnetic cellular spheroids for vascular tissue engineering. Biomaterials. 2014;35(3):949-960.

17. Lin Q, Ding X, Qiu F, Song X, Fu G, Ji J. In situ endothelialization of intravascular stents coated with an anti-CD34 antibody functionalized heparin-collagen multilayer. Biomaterials. 2010;31(14): 4017-4025.

18. Collet G, Grillon C, Nadim M, Kieda C. Trojan horse at cellular level for tumor gene therapies. Gene. 2013;525(2):208-216.

19. He Y, Cheng G, Xie L, Nie Y, He B, Gu Z. Polyethyleneimine/ DNA polyplexes with reduction-sensitive hyaluronic acid derivatives shielding for targeted gene delivery. Biomaterials. 2013;34(4): 1235-1245

20. Munier S, Messai I, Delair T, Verrier B, Ataman-Önal Y. Cationic PLA nanoparticles for DNA delivery: comparison of three surface polycations for DNA binding, protection and transfection properties. Colloids Surf B Biointerfaces. 2005;43(3):163-173.

21. Zhang H, Jia X, Han F, et al. Dual-delivery of VEGF and PDGF by double-layered electrospun membranes for blood vessel regeneration. Biomaterials. 2013;34(9):2202-2212.

22. Sun HY, Wei SP, Xu RC, Xu PX, Zhang WC. Sphingosine-1-phosphate induces human endothelial VEGF and MMP-2 production via transcription factor ZNF580: novel insights into angiogenesis. Biochem Biophys Res Commun. 2010;395(3):361-366.

23. Shi C, Yuan W, Khan M, et al. Hydrophilic PCU scaffolds prepared by grafting PEGMA and immobilizing gelatin to enhance cell adhesion and proliferation. Mater Sci Eng C Mater Biol Appl. 2015;50: 201-209.

24. Li Q, Shi C, Zhang W, Behl M, Lendlein A, Feng Y. Nanoparticles complexed with gene vectors to promote proliferation of human vascular endothelial cells. Adv Healthc Mater. 2015;4(8):1225-1235.

25. Khan M, Yang J, Shi C, et al. Surface modification of polycarbonate urethane with zwitterionic polynorbornene via thiol-ene click-reaction to facilitate cell growth and Proliferation. Macromol Mater Eng. 2015; 300(8):802-809.
26. Khan M, Yang J, Shi C, Lv J, Feng Y, Zhang W. Surface tailoring for selective endothelialization and platelet inhibition via a combination of SI-ATRP and click chemistry using Cys-Ala-Gly-peptide. Acta Biomater. 2015;20:69-81.

27. Shi C, Yao F, Huang J, et al. Proliferation and migration of human vascular endothelial cells mediated by ZNF580 gene complexed with mPEGb-P(MMD-co-GA)-g-PEI microparticles. J Mater Chem B. 2014;2(13): $1825-1837$.

28. Wang H, Feng Y, Yang J, Guo J, Zhang W. Targeting REDV peptide functionalized polycationic gene carrier for enhancing the transfection and migration capability of human endothelial cells. J Mater Chem B. 2015;3:3379-3391.

29. Hao X, Li Q, Lv J, et al. CREDVW-linked polymeric micelles as a targeting gene transfer vector for selective transfection and proliferation of endothelial cells. ACS Appl Mater Interfaces. 2015;7(22): 12128-12140

30. Merdan T, Kopeček J, Kissel T. Prospects for cationic polymers in gene and oligonucleotide therapy against cancer. Adv Drug Deliv Rev. 2002;54(5):715-758.

31. Lv J, Hao X, Yang J, Feng Y, Behl M, Lendlein A. Self-assembly of polyethylenimine-modified biodegradable complex micelles as gene transfer vector for proliferation of endothelial cells. Macromol Chem Phys. 2014;215(24):2463-2472.

32. Funhoff AM, Van Nostrum CF, Lok MC, Fretz MM, Crommelin DJ, Hennink WE. Poly (3-guanidinopropyl methacrylate): a novel cationic polymer for gene delivery. Bioconjug Chem. 2004;15(6):1212-1220.

33. Sun J, Zeng F, Jian H, Wu S. Grafting zwitterionic polymer chains onto PEI as a convenient strategy to enhance gene delivery performance. Polym Chem. 2013;4(24):5810-5818.

34. Xu FJ, Zhang ZX, Ping Y, Li J, Kang ET, Neoh KG. Star-shaped cationic polymers by atom transfer radical polymerization from $\beta$-cyclodextrin cores for nonviral gene delivery. Biomacromolecules. 2009;10(2): 285-293.

35. Tian HY, Deng C, Lin H, et al. Biodegradable cationic PEG-PEI-PBLG hyperbranched block copolymer: synthesis and micelle characterization. Biomaterials. 2005;26(20):4209-4217.

36. Yang YY, Wang X, Hu Y, Hu H, Wu DC, Xu FJ. Bioreducible POSScored star-shaped polycation for efficient gene delivery. ACS Appl Mater Interfaces. 2013;6(2):1044-1052.

37. Georgiou TK, Phylactou LA, Patrickios CS. Synthesis, characterization, and evaluation as transfection reagents of double-hydrophilic star copolymers: effect of star architecture. Biomacromolecules. 2005; 6(6):2990-2997.

38. Hung WC, Chang HC. Indole-3-carbinol inhibits Sp1-induced matrix metalloproteinase-2 expression to attenuate migration and invasion of breast cancer cells. J Agric Food Chem. 2009;57(1):76-82.

39. Gebhart C, Sriadibhatla S, Vinogradov S, Lemieux P, Alakhov V, Kabanov AV. Design and formulation of polyplexes based on pluronicpolyethyleneimine conjugates for gene transfer. Bioconjug Chem. 2002;13(5):937-944.

40. Yang J, Zhang P, Tang L, et al. Temperature-tuned DNA condensation and gene transfection by PEI-g-(PMEO2MA- $b$-PHEMA) copolymerbased nonviral vectors. Biomaterials. 2010;31(1):144-155.

41. Zuidam N, Posthumab G, de Vries ET, Crommelin DJ, Hennink WE, Storm G. Effects of physicochemical characteristics of poly (2-(dimethylamino) ethyl methacrylate)-based polyplexes on cellular association and internalization. J Drug Target. 2000;8(1):51-66.

42. Zhang QF, Yi WJ, Wang B, et al. Linear polycations by ring-opening polymerization as non-viral gene delivery vectors. Biomaterials. 2013; 34(21):5391-5401.

43. Fischer D, Li Y, Ahlemeyer B, Krieglstein J, Kissel T. In vitro cytotoxicity testing of polycations: influence of polymer structure on cell viability and hemolysis. Biomaterials. 2003;24(7):1121-1131.

44. Zubair M, Ekholm A, Nybom H, Renvert S, Widen C, Rumpunen K. Effects of Plantago major L. leaf extracts on oral epithelial cells in a scratch assay. J Ethnopharmacol. 2012;141(3):825-830. 
45. Liang C, Park AY, Guan J. In vitro scratch assay: a convenient and inexpensive method for analysis of cell migration in vitro. Nat Protoc. 2007; 2(2):329-333

46. Kircheis R, Wightman L, Schreiber A, et al. Polyethylenimine/DNA complexes shielded by transferrin target gene expression to tumors after systemic application. Gene Ther. 2001;8(1):28-40.

47. Baker A, Saltik M, Lehrmann H, et al. Polyethylenimine (PEI) is a simple, inexpensive and effective reagent for condensing and linking plasmid DNA to adenovirus for gene delivery. Gene Ther. 1997;4(8): 773-782.

48. Holycross D, Chai M. Comprehensive NMR studies of the structures and properties of PEI polymers. Macromolecules. 2013;46(17): 6891-6897.
49. Zhang Z, Ni J, Chen L, Yu L, Xu J, Ding J. Biodegradable and thermoreversible PCLA-PEG-PCLA hydrogel as a barrier for prevention of post-operative adhesion. Biomaterials. 2011;32(21):4725-4736.

50. Endres TK, Beck-Broichsitter M, Samsonova O, Renette T, Kissel TH. Self-assembled biodegradable amphiphilic PEG-PCL-PEI triblock copolymers at the borderline between micelles and nanoparticles designed for drug and gene delivery. Biomaterials. 2011;32(30): 7721-7731.
International Journal of Nanomedicine

\section{Publish your work in this journal}

The International Journal of Nanomedicine is an international, peerreviewed journal focusing on the application of nanotechnology in diagnostics, therapeutics, and drug delivery systems throughout the biomedical field. This journal is indexed on PubMed Central, MedLine, CAS, SciSearch $®$, Current Contents $\AA /$ Clinical Medicine,

\section{Dovepress}

Journal Citation Reports/Science Edition, EMBase, Scopus and the Elsevier Bibliographic databases. The manuscript management system is completely online and includes a very quick and fair peer-review system, which is all easy to use. Visit http://www.dovepress.com/ testimonials.php to read real quotes from published authors.

Submit your manuscript here: http://www.dovepress.com/international-journal-of-nanomedicine-journal 